\title{
Transient Analysis for Hypersonic Inlet Accelerative Restarting Process
}

\author{
Wei-Yi SU ${ }^{1}$ \\ Jiangsu Province Key Laboratory of Aerospace Power Systems, Nanjing University of Aeronautics and \\ Astronautics, Nanjing, China, 210016 \\ ZhiWei Hu ${ }^{2}$ \\ Aerodynamics and Flight Mechanics Research Group , Faculty of Engineering and the Environment, University of \\ Southampton, Southampton, SO17 1BJ, United Kingdom \\ Piao-Ping Tang ${ }^{3}$, Yun Chen ${ }^{4}$ \\ Jiangsu Province Key Laboratory of Aerospace Power Systems, Nanjing University of Aeronautics and \\ Astronautics, Nanjing, China, 210016
}

A three-dimensional computational fluid dynamics code which solves the unsteady compressible Reynolds-averaged Navier-Stokes equations was utilized to investigate the transient accelerative restarting processes of a two-dimensional hypersonic inlet. The characteristics of the accelerative restarting process were analyzed, and it reveals that the wall pressure time histories can be utilized to monitor whether the hypersonic inlet restarts. In addition, the effects of acceleration and flight trajectories on the transient accelerative process were studied. The results show that the process that the disappearance of separation bubble is delayed as the acceleration increases. As a result, the corresponding flight Mach number at which the inlet restarts increases accordingly. The unsteady simulation results also indicate that the trajectory has great impact on the accelerative restarting process.

\section{Nomenclature}

$$
\begin{aligned}
& a=\text { speed of sound } \\
& a_{0}=\mathrm{dV} / \mathrm{dt} \text {, the slope of } V-t \text { curve } \\
& b^{R}=\text { maximum characteristic speeds at different locations } \\
& b^{L}=\text { minimum characteristic speeds at different locations }
\end{aligned}
$$

\footnotetext{
${ }^{1}$ Associate professor, College of Energy and Power Engineering, Nanjing University of Aeronautics and Astronautics, weiyi_su@nuaa.edu.cn.

${ }^{2}$ Lecturer, Faculty of Engineering and the Environment, University of Southampton, Z.Hu@soton.ac.uk.

${ }^{3}$ Graduate student, College of Energy and Power Engineering, Nanjing University of Aeronautics and Astronautics

${ }^{4}$ Graduate student, College of Energy and Power Engineering, Nanjing University of Aeronautics and Astronautics
} 


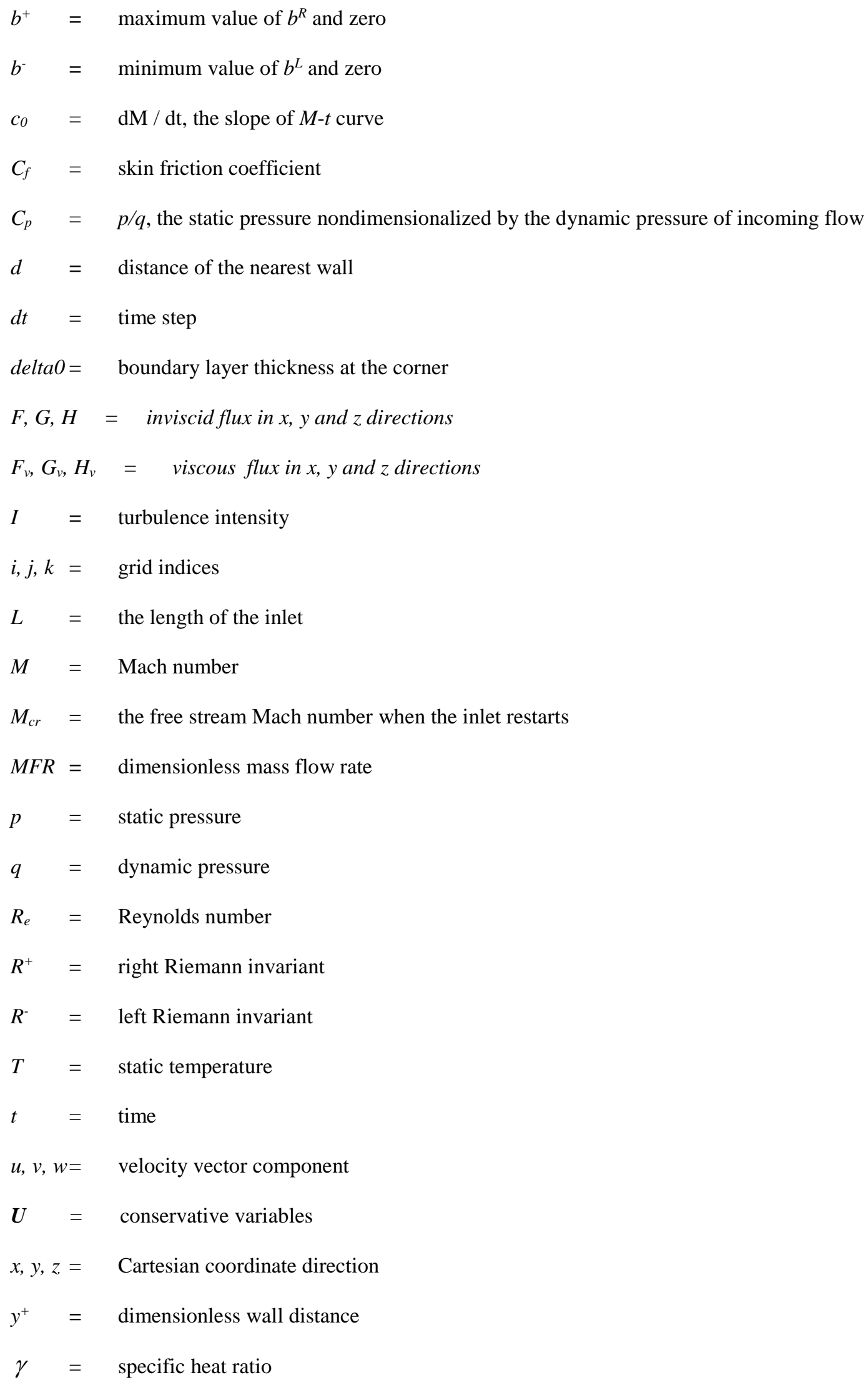




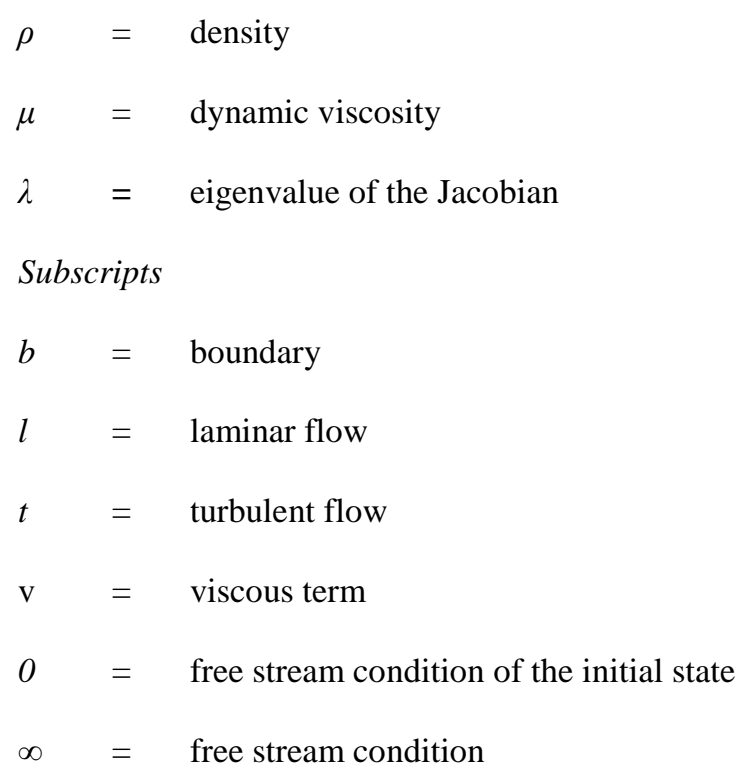

\section{Introduction}

Wypersonic inlet is the key component that captures and compresses air for scramjet combustors. To achieve an efficient operation with moderate induced drag, mixed external/internal compression inlets are often employed in scramjet [1]. However, the introduction of internal compression may result in difficulties in inlet self-starting, especially for over-contracted inlet [2].

The scramjet inlet must work in started state for the engine to operate regularly. As a result, it is very important to develop some methods to prevent the inlet from undergoing unstart [3-6]. On the other hand, if an inlet undergoes unstart, it should have the ability to restart rapidly and reliably. Therefore, inlet restart is essential for the successful operation of scramjet engines.

It has been known that the supersonic inlet can self-start without any external assist if its internal contraction ratio does not exceed Kantrowitz limit [2]. However, as the internal contraction ratios of most scramjet inlets lie in the dual solution area [7], the inlets cannot self-start again if they have undergone unstart previously. Consequently, measures should be taken to assist the inlets to restart quickly at any cost.

The issues of supersonic inlet restart have been investigated for several decades [1-2]. It has been found that the Reynolds number and the geometry parameters especially the internal contraction ratio can affect the restarts of supersonic inlets to a great extend [1]. Therefore, using variable geometries is a viable method for most ramjet/scramjet inlets [8-14], however, the weight and complexity can significantly degrade the total performance of scramjet engines and there still exist many challenges [15]. 
On the other hand, it has been found from many experiments that some inlets that cannot restart in continuous wind tunnels have restarted in pulse facilities [16, 17]. Therefore, utilization of the unsteady effects may be a viable approach to circumvent the quasi-steady assumptions of Kantrowitz limit and assist the scramjet inlet to restart [1819].

The unsteadiness can be induced by many methods such as impulsive acceleration or sudden rupture of the diaphragm which refers to the door sealing the entrance of the inlet. In recent years, the latter unsteady starting methods have been explored with Reynolds Averaged Navier-Stokes simulations [8-12]. However, for the accelerative restarting method, although two-dimensional inviscid simulations have been carried out to verify the efficacy of accelerative unsteadiness on the starting issues of a radius Busemann inlet [18, 19], viscous simulation about the accelerative restarting process of two-dimensional planar inlet is still scarce, and the effects of acceleration-induced unsteadiness on the hypersonic inlet restarting process still remain unclear.

In addition, the dynamic pressures and Reynolds number of the incoming flow often change with the flight Mach number and altitude in real flight experiments [20]. However, little attention has been paid to the effects of trajectory on the hypersonic inlet accelerative restarting process.

In the present research, a three-dimensional computational fluid dynamic code was developed to solve the Reynolds Averaged Navier-Stokes equations and the transient physics of hypersonic inlets restart assisted by impulsive acceleration were investigated. Moreover, the magnitude of the impulsive acceleration and trajectories on the restarting process were examined for the hypersonic planar inlet.

\section{Model and Computational Methods}

\section{A. Numerical Methods}

A three-dimensional computational fluid dynamics code based on muti-block structured grids was utilized to solve the non-dimensionalized conservation Reynolds-averaged Navier-Stokes Equations

$$
\frac{\partial U}{\partial t}+\frac{\partial F}{\partial x}+\frac{\partial G}{\partial y}+\frac{\partial H}{\partial z}=\frac{\partial F_{v}}{\partial x}+\frac{\partial G_{v}}{\partial y}+\frac{\partial H_{v}}{\partial z}
$$

SST k- $\omega$ turbulence model was adopted [21]. Compressibility corrections were employed for this turbulence model as suggested by Wilcox [22], where the ratio of the dilatation dissipation to the solenoidal dissipation was 
modeled as a function of turbulence Mach number. The laminar and turbulent Prandtl number were set at 0.72 and 0.9 , respectively.

The inviscid flux vectors in Equation (1) were discreted using HLLE schemes developed by Harten, et al [23]. For example, the inviscid flux vector in i-direction is

$$
F_{i+1 / 2}\left(U_{i}+U_{i+1}\right)=\frac{1}{2}\left[F\left(U_{i}\right)+F\left(U_{i+1}\right)\right]-\frac{1}{2} \sum_{k=1}^{2} \alpha_{k}\left|q_{k}\right| R_{k}
$$

where

$$
\begin{gathered}
q_{k}=\frac{b^{+}+b^{-}}{b^{+}-b^{-}} \lambda_{k}-\frac{2 b^{+} b^{-}}{b^{+}-b^{-}} \\
b^{+}=\max \left(b^{R}, 0\right) \\
b^{-}=\min \left(b^{L}, 0\right)
\end{gathered}
$$

In equations (3) to (5), $\alpha_{k}$ and $R_{k}$ are the average approximate wave strengths and eigenvectors respectively. $\lambda_{k}, b^{R}$ and $b^{L}$ are the eigenvalues, maximum and minimum characteristic speeds at different locations.

In order to improve the accuracy, the MUSCL (Monotone Upstream-Centred Schemes for Conservation Laws) scheme was utilized to interpolate the primitive variables. For example, density on the left and right of the cell faces in computing the convective flux through the cell faces is calculated as follows [24]

$$
\begin{aligned}
& \rho_{L}=\rho_{i}\left\{1+\frac{\varepsilon}{4}\left[(1+k) \Delta_{+}+(1-k) \Delta_{-}\right]\right\} \\
& \rho_{R}=\rho_{i+1}\left\{1-\frac{\varepsilon}{4}\left[(1+k) \Delta_{-}+(1-k) \Delta_{+}\right]\right\}
\end{aligned}
$$

In Equations (6) and (7), $\varepsilon$ is a flag which controls the order or higher order of the reconstruction. If $\varepsilon$ equals zero, a first order reconstruction is performed. If $\varepsilon$ is 1.0 , higher order reconstruction can be obtained. The range of $\hat{k}$ is between -1 and 1 . As $\hat{k}=1 / 3$, a third order reconstruction is obtained, which was used in this research.

An implicit dual time stepping algorithm was employed for the unsteady term in equation (1), and second-order temporal accuracy was obtained by utilizing a three-point backward difference in the sub-iteration procedure [25]. 


\section{B. Computational Model}

1 . Inlet geometry

As the focus of this research is to investigate the effect of acceleration on the restarting process of hypersonic inlet, the impacts of sidewall and aspect ratio were not addressed. A schematic of the two-dimensional mixed-compression inlet is shown Fig. 1. The turning angles of the external compression ramps are $7^{\circ}$ and $8^{\circ}$, respectively. The internal contraction ratio is 1.42 , and the curves from point 3 to point 5 and point 7 to point 9 are circular arcs. The coordinate values at different vertexes are listed in Tab. 1.

Table 1 Geometric parameters

\begin{tabular}{|c|c|}
\hline Vertexes & Coordinate values/mm \\
\hline 1 & 0,0 \\
\hline 2 & $190.35,20.00$ \\
\hline 3 & $338.42,54.19$ \\
\hline 4 & $373.42,61.90$ \\
\hline 5 & $408.81,67.60$ \\
\hline 6 & $518.81,67.60$ \\
\hline 7 & $333.62,75.00$ \\
\hline 8 & $376.66,80.67$ \\
\hline 9 & $408.81,82.60$ \\
\hline 10 & $518.81,82.60$ \\
\hline
\end{tabular}

Fig. 1 Schematic diagram of the inlet

\section{Boundary conditions}

A sketch map of the computational domain is shown in Fig. 2, which consists of two blocks. At the inflow boundaries of block-1 and block-2, free stream boundary conditions were used. For turbulence, the incoming turbulence kinetic energy can be calculated from the turbulence intensity $I_{\infty}$ and Mach number of the free stream $M_{\infty}$

$$
k=1.5 \times\left(I_{\infty} \times M_{\infty}\right)^{2}
$$

The incoming turbulent viscosity is set to 


$$
\mu_{t}=0.1 \mu_{l, \infty}
$$

The value of turbulence intensity is 0.001 , and the laminar viscosity can be calculated with Sutherland's law. Other turbulent parameters such as specific turbulence dissipation rate can be deduced from turbulence intensity and Mach number.

At the right and top boundary of block-2, supersonic outflow conditions were applied. While for the outflow boundary of block-1, as the scramjet isolator is affected by the back pressure induced by combustion in the combustor, a back pressure boundary condition was generally applied on the exit of the scramjet isolator in a previous study [26].

On the other hand, to explore the effect of acceleration on the restarting process of hypersonic inlets, the inlet should go into unstart first. Unstart can occur if the free stream Mach number is reduced sufficiently below the starting value, or the back pressure is increased to the point that the shock wave is expelled out of the throat. For the current research, the inlet unstart takes place at a free stream Mach number of 2.0. It is because that the free stream Mach number is below the starting value.

In order to simplify the discussion, we assume that the combustion does not happen in the combustor throughout the accelerative restarting process. As a result, there is no backpressure imposed on the exit of the inlet-isolator. Consequently, the Riemann invariant boundary conditions referred to as called Inflow/outflow condition in [27] is employed on the exit of the scramjet isolator during the simulation of the inlet accelerative restarting process. The velocity and speed of sound at the boundary are given by

$$
\begin{gathered}
u_{b}=\frac{1}{2}\left(R^{+}+R^{-}\right) \\
a_{b}=\frac{\gamma-1}{4}\left(R^{+}-R^{-}\right)
\end{gathered}
$$

where $R^{+}$and $R^{-}$are the Riemann invariants. The density and pressure at the boundary are given by

$$
\begin{gathered}
\rho_{b}=\left[\frac{a_{b}^{2}}{\gamma s_{b}}\right]^{\frac{1}{\gamma-1}} \\
p_{b}=\frac{\rho_{b} a_{b}^{2}}{\gamma}
\end{gathered}
$$


Details of the inflow/outflow boundary condition can be found in Ref. 27. After the inlet restarts, a supersonic flow field is established and extrapolation boundary conditions were applied on the exit of hypersonic inlet-isolator. The pressure, density and other flow parameters are extrapolated from the cell inside the domain adjacent to the boundary

$$
\begin{gathered}
p_{N}=p_{N-1} \\
\rho_{N}=\rho_{N-1}
\end{gathered}
$$

In Equation (14) and (15), $N$ is the index of grid point at the boundary. At the back and front boundaries along $\mathrm{z}$ direction, symmetry boundary conditions were used. Non-slip adiabatic wall boundary conditions were employed for all the walls.

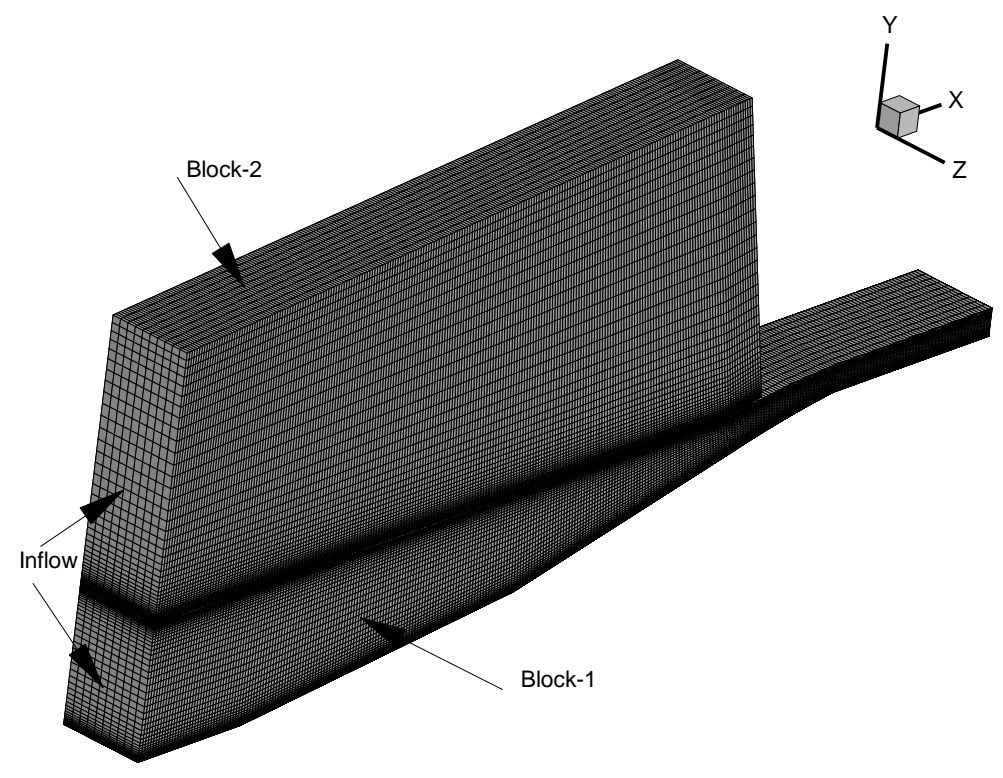

Fig. 2 Schematic of the computational grid

\section{Code Validation and Turbulence Model Sensitivity Analysis}

1. Turbulent flow over a flat plate

Supersonic flow over a flat plate was simulated to validate the turbulence model. The length of the flat plate is $1.0 \mathrm{~m}$, and the computational mesh is $400 \times 200 \times 3$ in the $x, y$, and $z$ directions, respectively. Computational parameters and the two-dimensional computation mesh at mid-plane are displayed in Table 2 and Fig. 3, where $d$ is the distance of the first cell to the wall. Fig. 4 gives the turbulent law of wall, which reveals that the computational results agree well with the theoretical results. 
Table 2 Computational Parameter

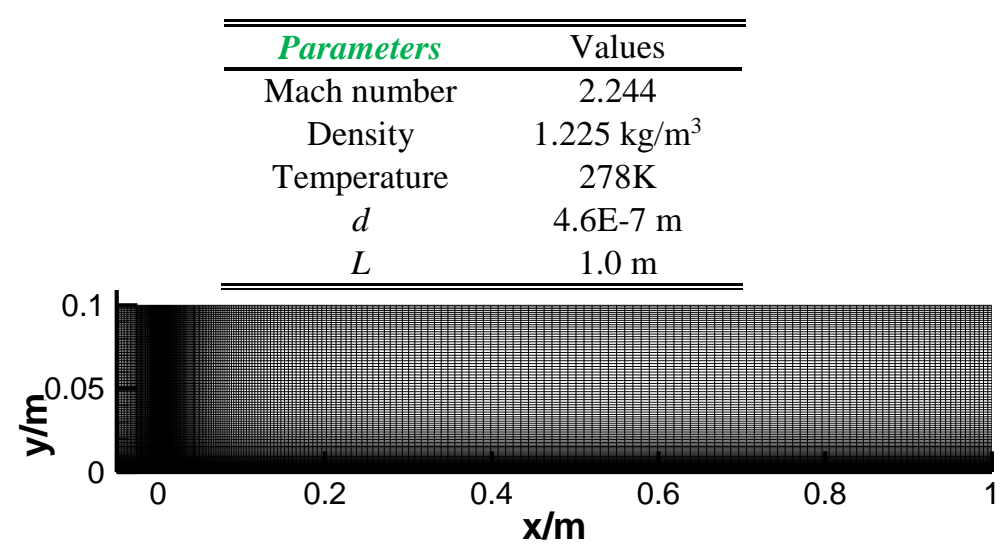

Fig. 3 Computational mesh at mid-plane

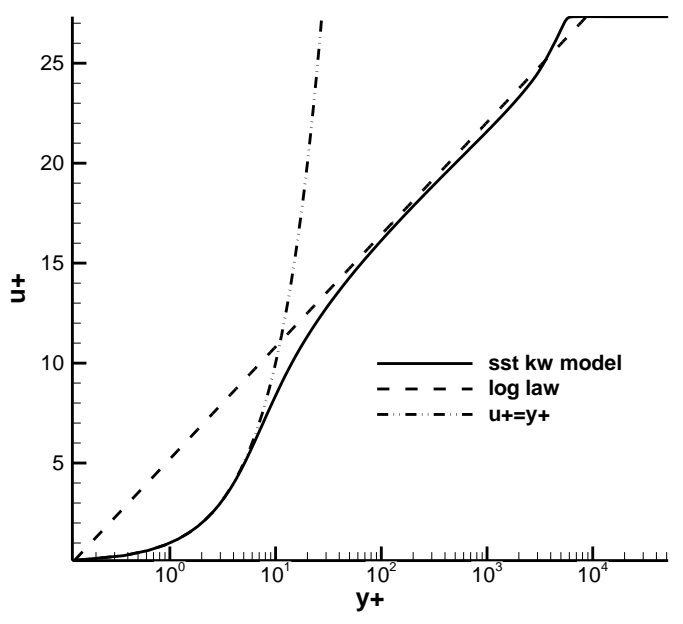

Fig. 4 Law of wall for supersonic flat plate turbulence

2. Turbulence modelling sensitivity analysis

Turbulence model sensitivity analysis was performed for different dimensionless distances. The values of $y+$ were set to $3.75,0.75$, and 0.15 , respectively. Fig. 5 implies that if $y+$ is less than 1.0 , the distribution of the skin friction coefficient agrees well with the theoretical result [28]. 


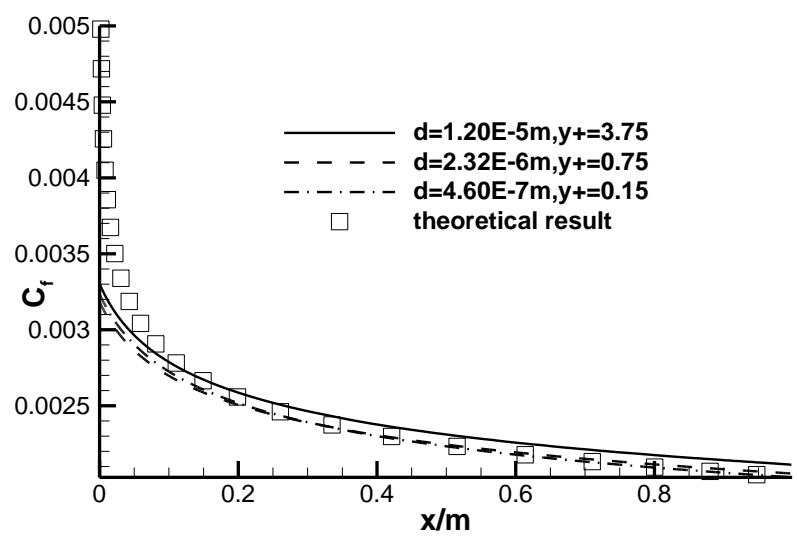

Fig. 5 Distributions of skin friction Coefficients under different wall distances

3. Two-dimensional compression corner flow

The experiment of a $24^{\circ}$-compression corner flow carried out by Kuntz et al [28] was for validation. The free stream Mach number, total pressure, total temperature, are $2.94,483 \mathrm{kPa}$, and $302.15 \mathrm{~K}$, respectively. The boundary layer thickness at the corner is $8.27 \mathrm{~mm}$.

The computational grid is $400 \times 101 \times 3$, and the two-dimensional computation mesh at mid-plane is shown in Fig. 6. The distance of the first grid to the wall is $0.001 \mathrm{~mm}$. Free stream boundary layer condition was applied on the inflow boundary. Supersonic out flow boundary conditions were used on the top and right boundaries. Non-slip adiabatic wall boundary conditions were employed for all the walls.

The wall pressure distribution obtained from current simulation is displayed in Fig. 7 and compared with experimental data. The pressure is non-dimensionalized with the free stream pressure, and the abscissa is nondimensionalized with the boundary layer thickness at the corner. It can be seen that the two-dimensional computational results give a reasonable agreement with the experimental results.

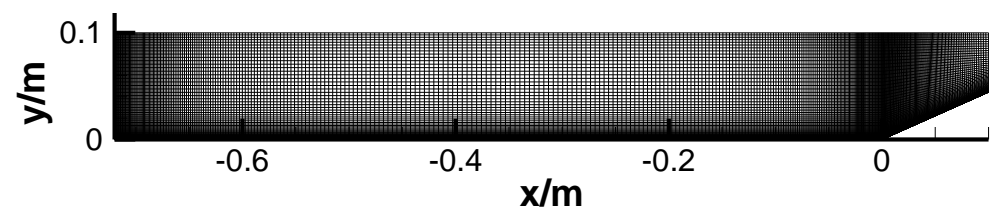

Fig. 6 Computational mesh at mid-plane 


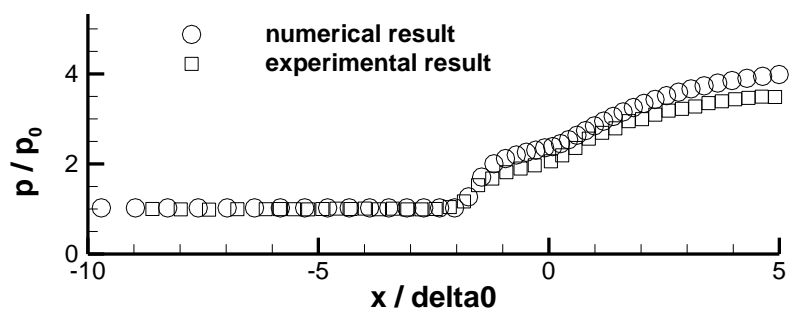

Fig. 7 Distributions of dimensionless wall pressure

In our previous research, the unstart process for a hypersonic inlet was also carried out, and it demonstrated that the unsteady simulation results accord well with the experimental data [26].

\section{Grid sensitivity Analysis for the Inlet Model}

Grid sensitivity analysis was carried out and the parameters for three grids are displayed in Tab. 3. The Mach number, pressure and temperature of the incoming flow are 2.0,31225 Pa, and $217 \mathrm{~K}$, respectively. In all the cases, the distances from the first cells to the walls are $0.001 \mathrm{~mm}$, which ensured that the values of $\mathrm{y}+$ at the first grid cells are less than 0.3 .

Table 3 Different Grid Densities

\begin{tabular}{ccc}
\hline \hline case & $\begin{array}{c}\text { Grid numbers on the bottom } \\
\text { block }\end{array}$ & $\begin{array}{c}\text { Grid numbers on the top } \\
\text { block }\end{array}$ \\
\hline Fine grid & $510 \times 121 \times 11$ & $449 \times 110 \times 11$ \\
Medium grid & $298 \times 81 \times 11$ & $223 \times 71 \times 11$ \\
Coarse grid & $140 \times 51 \times 11$ & $103 \times 41 \times 11$ \\
\hline \hline
\end{tabular}

Fig. 8 gives the distributions of bottom wall pressure and skin friction coefficient under different grid densities. It indicates that although the grid densities are different, the results are almost the same. Therefore, the medium grid density was employed for the further study. 


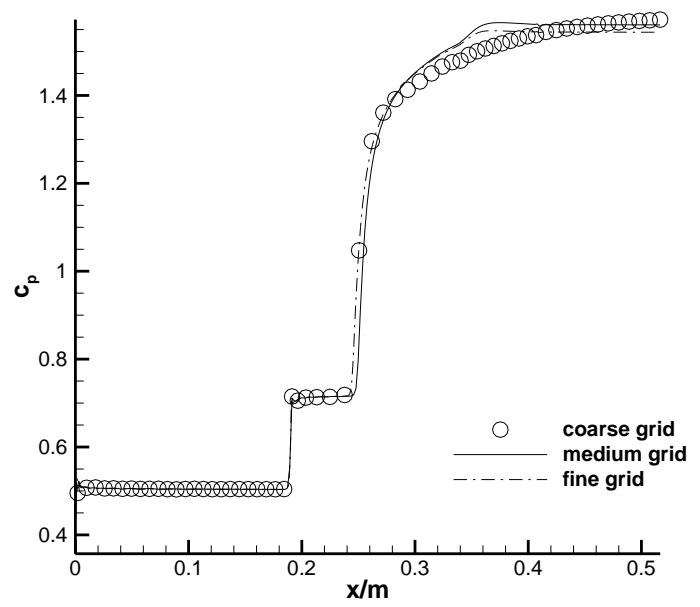

(a) Wall pressures coefficient

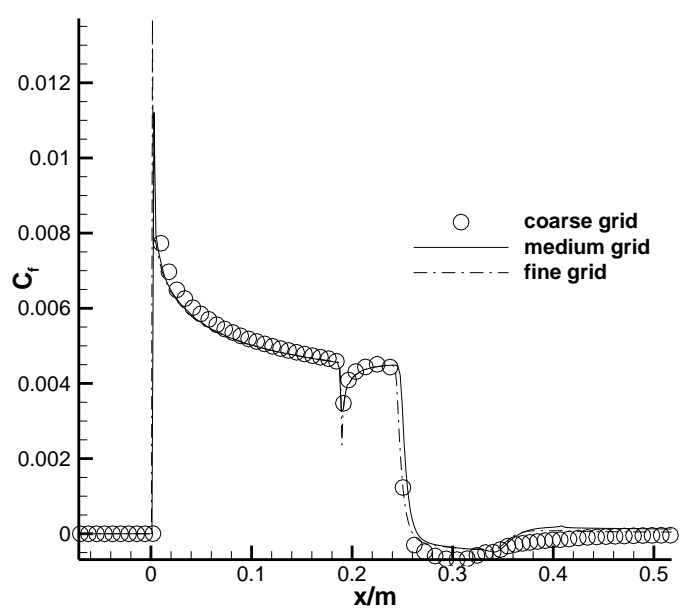

(b) Skin friction coefficient

Fig. 8 Distributions of bottom wall parameters under different grid densities

\section{E. Initial Unstart Flow Field and Acceleration Model}

In order to simulate the accelerative restarting process, an initial unstart flow field is needed for further computation. In this research, unstart was induced for a free stream Mach number sufficiently below the starting value. The Mach number, static pressure and temperature are 2.0, $31225 \mathrm{~Pa}$, and $217 \mathrm{~K}$, respectively. The corresponding Reynolds number based on the inlet length and free stream flow conditions is 19907944.

The Mach number contour and streamline near the inlet cowl are presented in Fig. 9. It shows that the inlet undergoes unstart and the separation bubble is pushed out of the inlet throat. This flow field will be used as the initial field for further computation of the accelerative restarting process. 


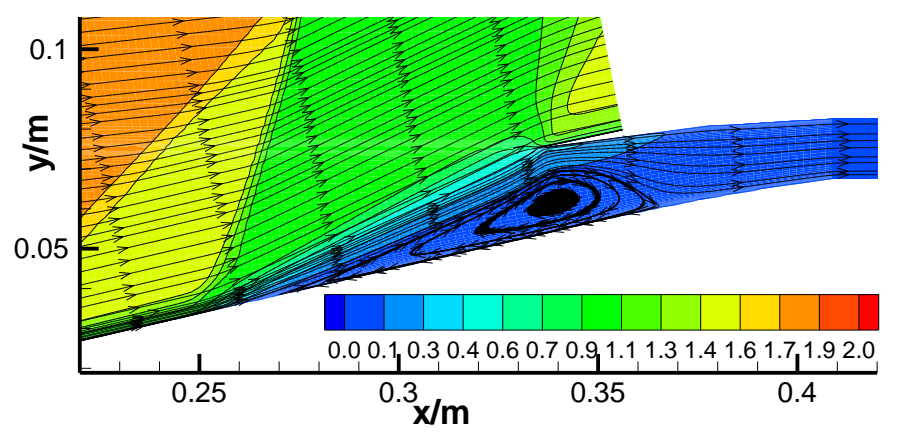

Fig. 9 Mach number contours and streamlines near the inlet cowl

Although the trajectory in flight experiments $[20,30]$ is very complex, in order to simplify the acceleration process, a linear relation between the flight Mach number and time was assumed

$$
M=M_{0}+c_{0} t
$$

The parameter $\mathrm{c}_{0}$ is the acceleration of the flight Mach number. $M_{0}$ is the initial flight Mach number, at which the inlet underwent unstart, which is set to 2.0 in this study.

In order to explore the effects of trajectory on the accelerative restarting process of hypersonic inlets, two kinds of trajectories were explored. One is constant dynamic pressure trajectory, and the other is a trajectory with altitude constant height. In all the computational cases, the dimensionless time step $d t$ is 0.001 . For the case that incoming Mach number is 2.0, the maximum value of Courant number is 25 .

\section{Computational Results}

\section{A. Characteristics of Accelerative Restarting Process}

Flight experiments showed that the value of $c_{0}$ can reach about $0.2 \sim 0.4 \mathrm{~s}^{-1}[20,30]$. Hence, the accelerative restarting process of $c_{0}=1.475 \mathrm{~s}^{-1}$ was studied first. Moreover, the accelerative process was investigated under a constant dynamic pressure trajectory.

As the dynamic pressure does not change for this trajectory, the bottom wall pressure histories are nondimensionalized by the dynamic pressure at the initial state $q_{0}$. Fig. 10 and Fig. 11 show that there is a turning point in the pressure history at $t=2101.69 \mathrm{~ms}$ about, after which the wall pressure decreases sharply to a trough value. 


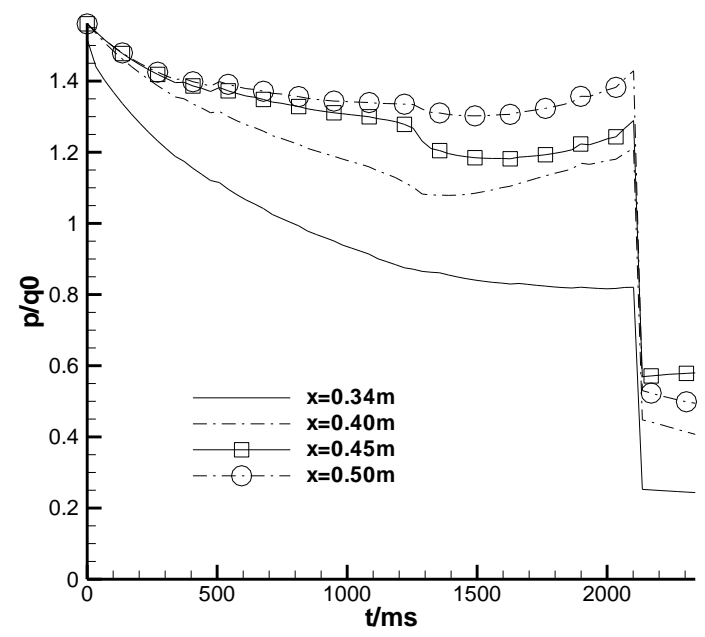

Fig. 10 Pressure histories at the lower wall, $c_{0}=1.475 \mathrm{~s}^{-1}$

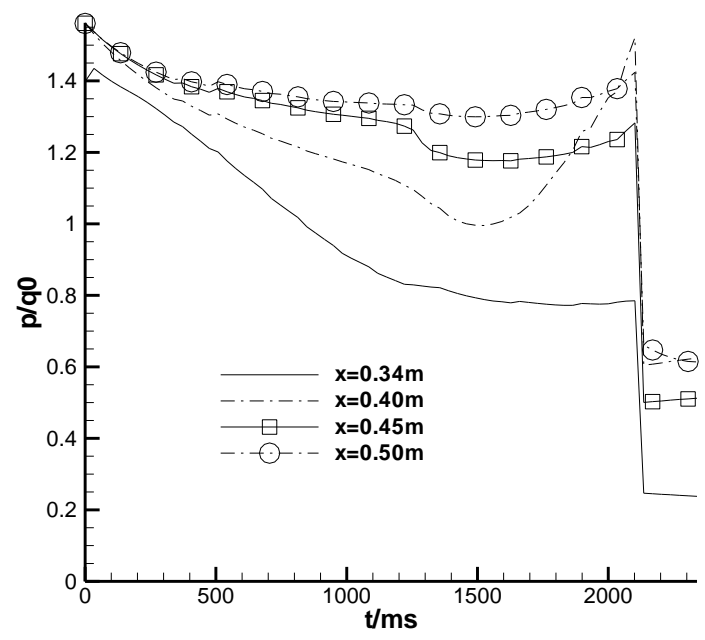

Fig. 11 Pressure histories at the upper wall, $c_{0}=1.475 \mathrm{~s}^{-1}$

In order to reveal the transient physics during the accelerative process, the Mach number contours ranging from 0 to 1 at different time instances are presented in Fig. 12. Figure 12 (a) displays that the flow within the internal compression section is subsonic at the initial stage of the accelerative process. However, with the increase of flight Mach number, local supersonic flow appears and a normal shock wave is generated near the inlet cowl, which is shown in Fig. 12 (b). After that, the normal shock wave disappears, and a fluidic throat is formed beneath the cowl. The sonic line moves downstream towards the isolator exit with the increase of flight Mach number, which can be seen in the sequence of Fig. 12 (b), Fig. 12 (c) and Fig. 12 (d). At $t=1796.61$ ms, part of the flow at the exit reach sonic speed, but the separation bubble will last for a certain period. Fig. 12 (d) and Fig. 12 (e) show that the separation bubble does not vanish until $t=2135.59 \mathrm{~ms}$. 
The transition from choked flow to supersonic flow is one of the characteristics that hypersonic inlet restarts. Moreover, Fig. 10, Fig. 11 and Fig. 12 show that the vanishing of the separation bubble can cause the pressure within the inlet to decrease sharply to a trough value in the restarting process. Therefore, the pressure histories in the inlet can be utilized to judge whether the separation bubble has been eliminated during the accelerative restarting process.

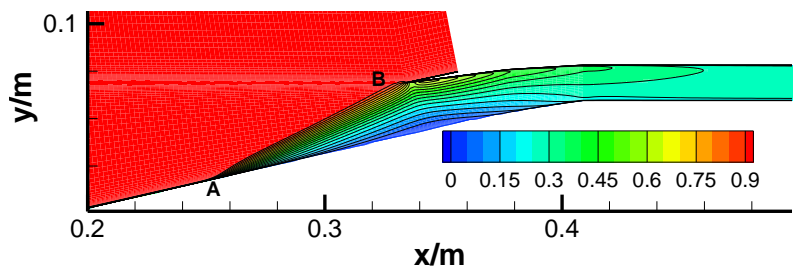

(a) $t=33.90 \mathrm{~ms}$

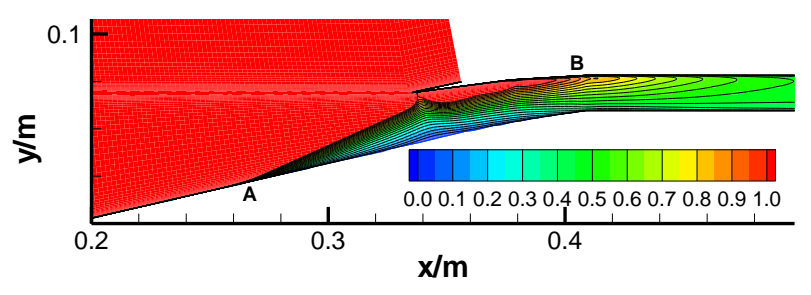

(b) $t=1118.64 \mathrm{~ms}$

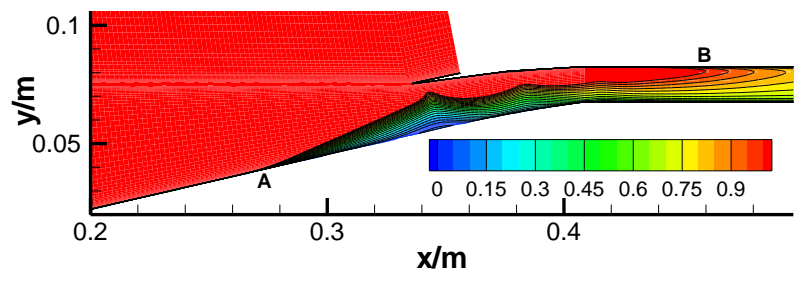

(c) $t=1457.63 \mathrm{~ms}$

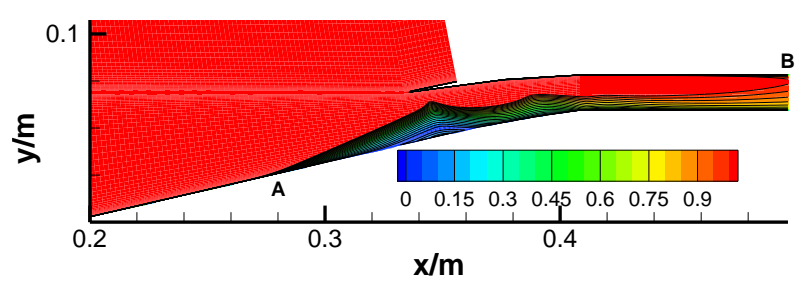

(d) $t=1796.61 \mathrm{~ms}$

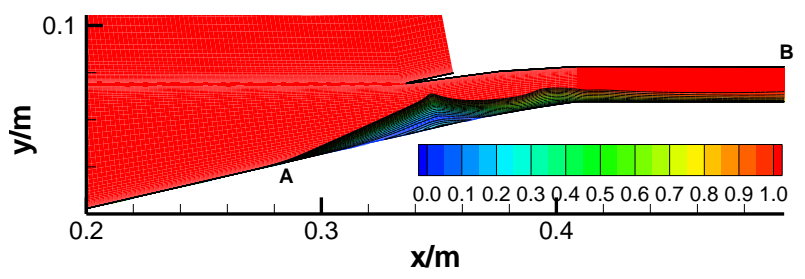

(e) $t=2101.69 \mathrm{~ms}$ 


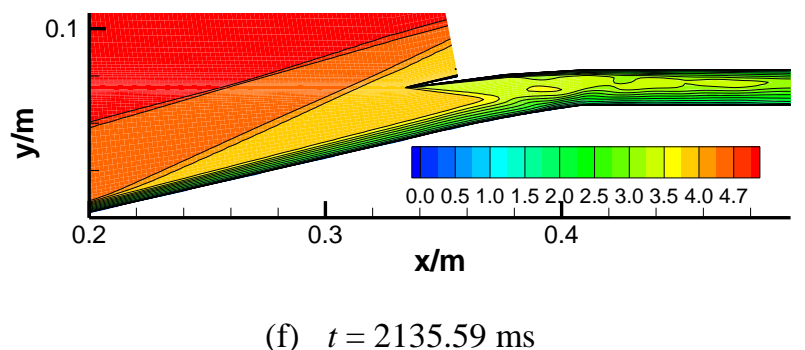

Fig. 12 Mach number contours at different time, $c_{0}=1.475 \mathrm{~s}^{-1}$

Distributions of the skin friction coefficients at different time are presented in Fig. 13. It shows that the skin friction coefficient increases with the flight Mach number in the accelerative restarting process. This may be attributed to the decrease of the Reynolds number as the flight Mach number and altitude increase for the constant dynamic pressure trajectory. Fig. 13 also implies that the skin friction coefficient changes significantly as the separation bubble diminishes at $t=2135.59 \mathrm{~ms}$. The value of the skin friction coefficient at that time is greater than zero, which indicates that the there is no separation bubble on the lower wall and the inlet restarts completely.

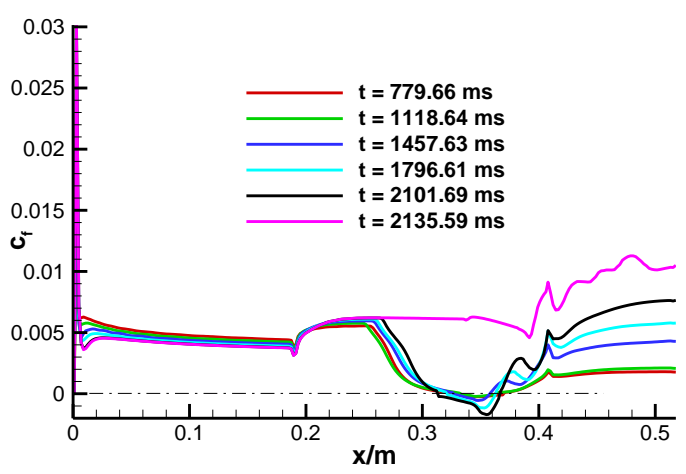

Fig. 13 Distributions of the skin friction coefficients along the lower wall, $c_{0}=1.475 \mathrm{~s}^{-1}$

The wall pressure distributions shown in Fig. 14 demonstrate that the static pressure of the incoming flow continues to decrease with the increase of flight Mach number and altitude for the constant dynamic pressure trajectory. Fig. 14 also reveals that the pressure after $x=0.26 \mathrm{~m}$ decrease sharply at $t=2135.59 \mathrm{~ms}$ due to the vanishment of the separation bubble. 


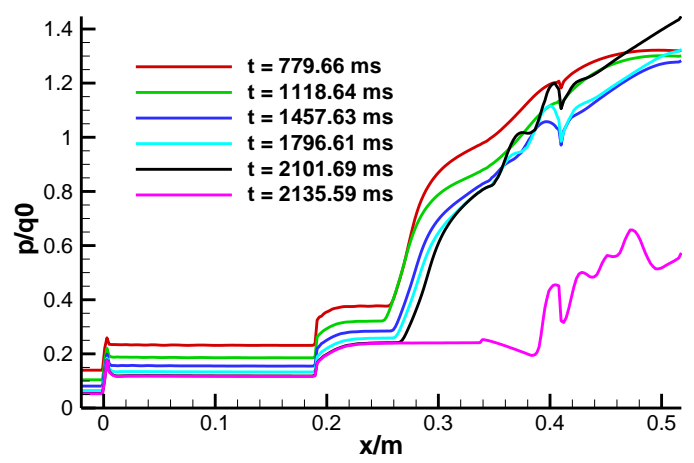

Fig. 14 Distributions of lower wall pressure at different time, $c_{0}=1.475 \mathrm{~s}^{-1}$

The restarting processes under other accelerations are similar to the case of $c_{0}=1.475 \mathrm{~s}^{-1}$. The separation bubble at the inlet throat vanishes as the wall pressure histories decreases to a trough value. This again confirms that the phenomenon can be utilized to detect whether the separation bubble has vanished.

\section{B. Effects of Impulsive Acceleration}

Unsteady simulations of hypersonic inlet restarting processes under different accelerations were carried out. The sequence of Mach number contours shown in Fig. 15 indicates that the separation bubble does not disappear until the flight Mach number is accelerated to 5.25 when $c_{0}$ equals $14.75 \mathrm{~s}^{-1}$. However, for $c_{0}$ equals $147.5 \mathrm{~s}^{-1}$, the separation bubble vanishes at the flight Mach number of 5.30, as shown in Fig. 16.

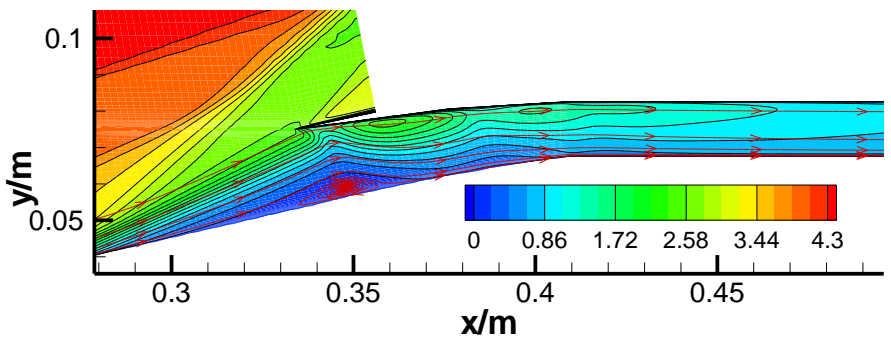

(a) $M=4.5$ 


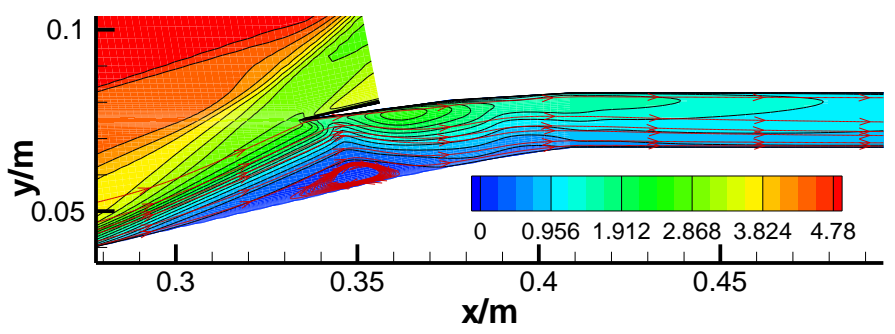

(b) $M=5.0$

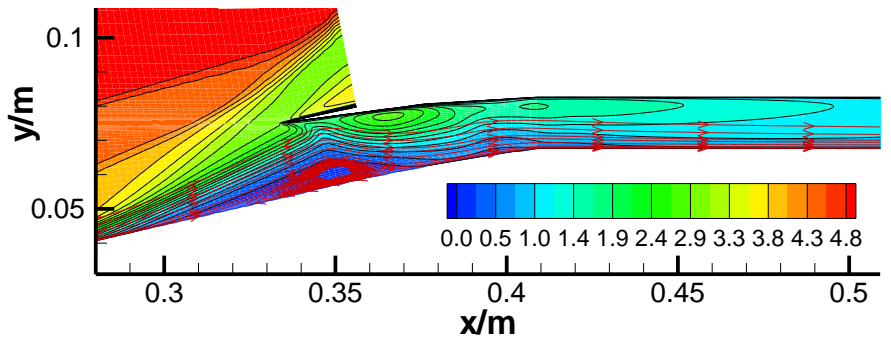

(c) $M=5.2$

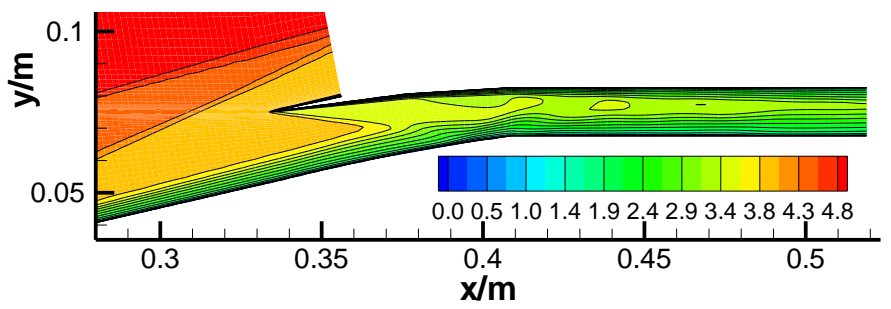

(d) $\quad M=5.25$

Fig. 15 Sequence of Mach number contours, $c_{0}=14.75 \mathrm{~s}^{-1}$

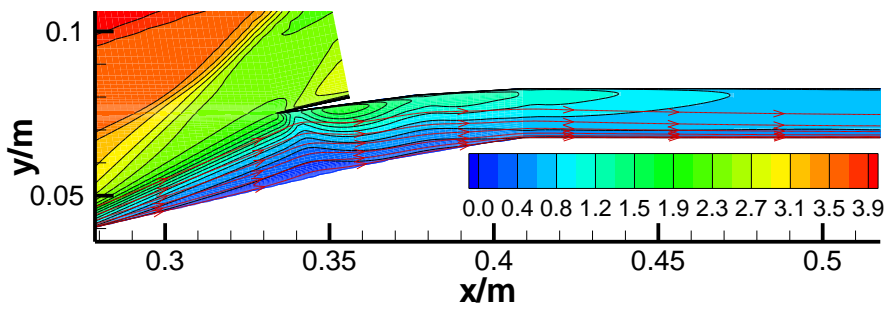

(a) $M=4.5$ 


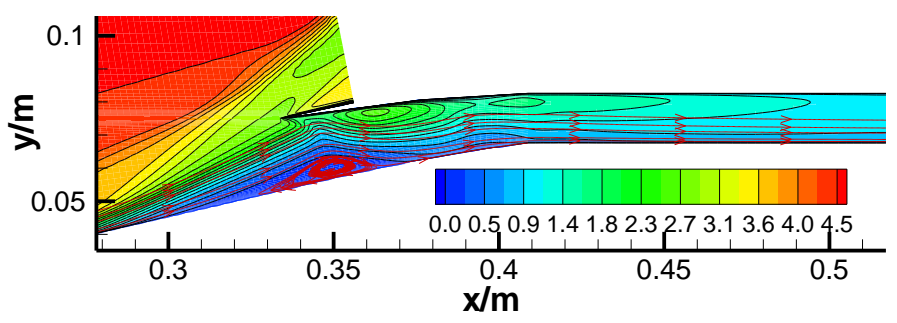

(b) $M=5.0$

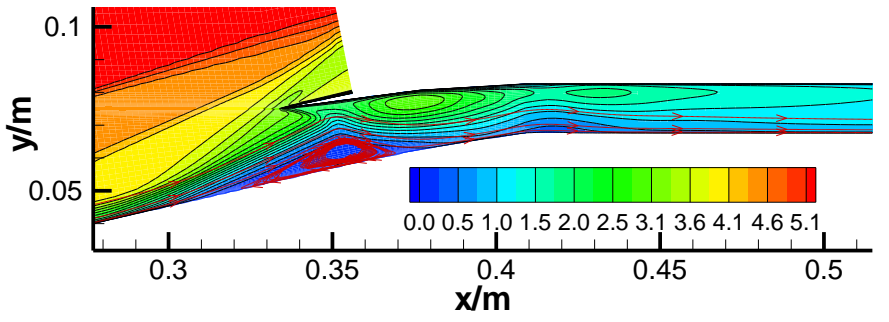

(c) $M=5.25$

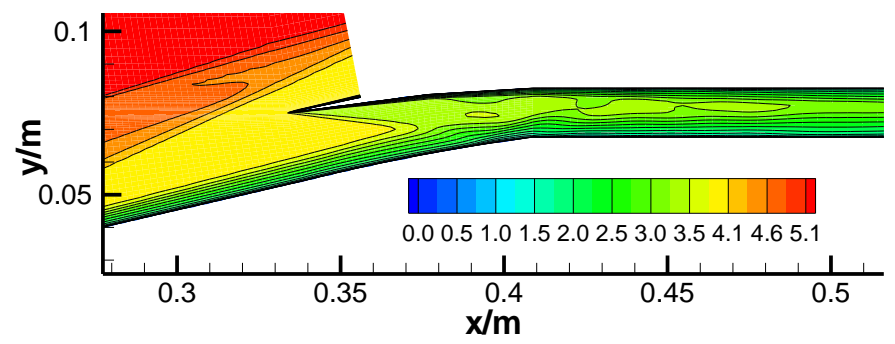

(d) $\quad M=5.3$

Fig. 16 Sequence of Mach number contours, $c_{0}=147.5 \mathrm{~s}^{-1}$

The dependence of acceleration on the disappearance of separation bubble in the accelerative process is presented in Fig. 17, where the Y-axis is the flight Mach number when the separation bubble vanishes completely. The result shows that the process that the separation bubble vanishes will be delayed for high accelerations. That is, the larger the acceleration is, the later the separation bubble disappears, and consequently the corresponding flight Mach number when separation bubble vanishes is increased.

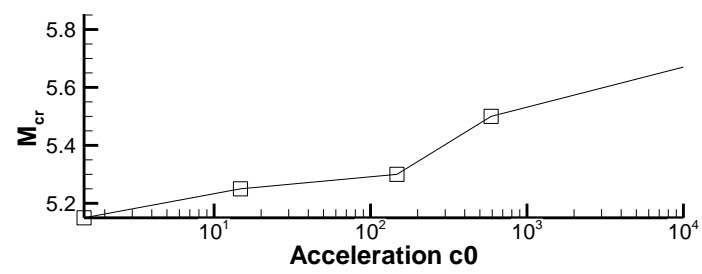

Fig. 17 Effect of acceleration $c_{0}$ on the Mach number at which separation bubble vanishes 
The wall pressure histories at $x=0.5 \mathrm{~m}$ under different acceleration $\mathrm{c}_{0}$ are displayed in Fig. 18. It reveals that the static pressure histories under different $c_{0}$ values are similar to the case of $c_{0}=1.475 \mathrm{~s}^{-1}$. That is, with the increase of flight Mach number, the static pressures will reach a turning point indicated on $\mathrm{A}^{\prime}, \mathrm{B}^{\prime}, \mathrm{C}^{\prime}$, and $\mathrm{D}^{\prime}$ in the plots, while after the turning points, the static pressures sharply decrease to trough values (A, B, C, and D), at which the separation bubble vanishes, supersonic flow is established and the inlet restarts completely. Fig. 18 shows that the Mach number and the local static pressures at $\mathrm{A}^{\prime}, \mathrm{B}^{\prime}, \mathrm{C}^{\prime}$, and $\mathrm{D}^{\prime}$ increase with the acceleration, which implies that the impulsive acceleration-induced unsteadiness can cause the inlet chocked more seriously at higher accelerations.

It can also be observed from Fig. 18 that after the inlet has restarted completely, the pressure history curves under different $c_{0}$ coincide, which means that although the acceleration $c_{0}$ affects the restarting process significantly, however, after the inlet restarts, the flow fields in the inlet are not affected by the acceleration.

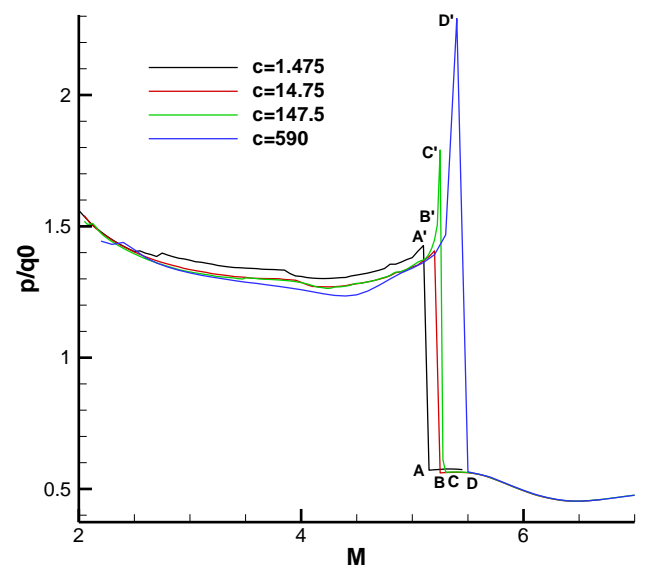

(a) At the bottom wall

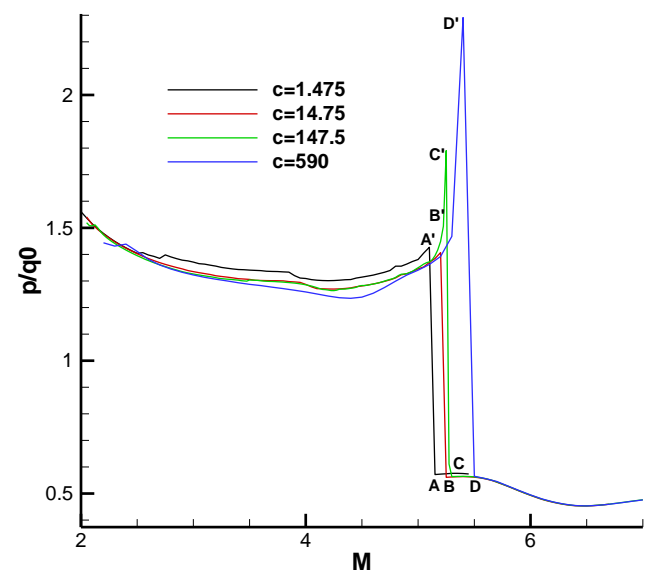

(b) At the upper wall

Fig. 18 Relations of wall pressure at $x=0.5 \mathrm{~m}$ with the flight Mach number during the restarting process 


\section{Effects of Flight Trajectories}

To explore the effects of flight trajectories on the accelerative restart of the inlet, the restarting processes from the same unstarted state $\left(\mathrm{M}_{0}=2.0\right)$ under different trajectories were carried out. Two type of trajectory, namely the constant dynamic pressure trajectory(CDPT) and the constant altitude trajectory(CAT) were tested.

A sequence of Mach number contours in the accelerative process for the constant altitude trajectory is presented in Fig. 19. It shows that the separation bubble does not vanish until the flight Mach number is accelerated to 4.5. By contrast, Fig. 20 implies that the separation bubble disappears as the flight Mach number is accelerated to 5.5 for the constant dynamic pressure trajectory.

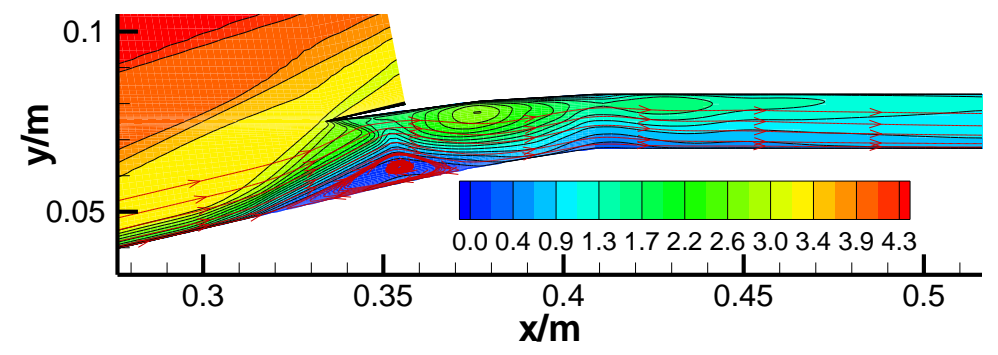

(a) Flight Mach number is accelerated to 4.45

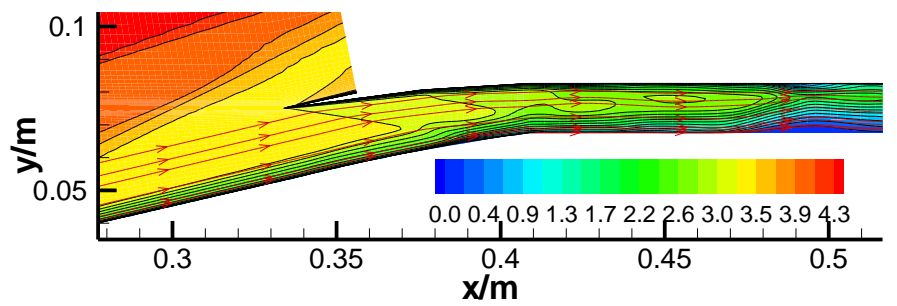

(b) Flight Mach number is accelerated to 4.475

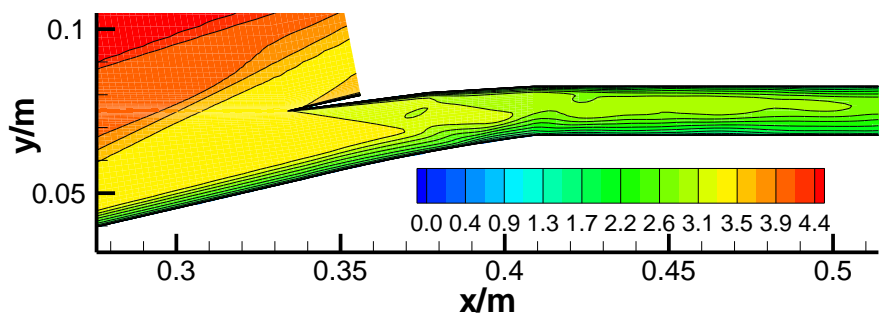

(c) Flight Mach number is accelerated to 4.5

Fig. 19 Sequence of Mach number in the restarting process for constant altitude trajectory, $c_{0}=147.5 \mathrm{~s}^{-1}$ 


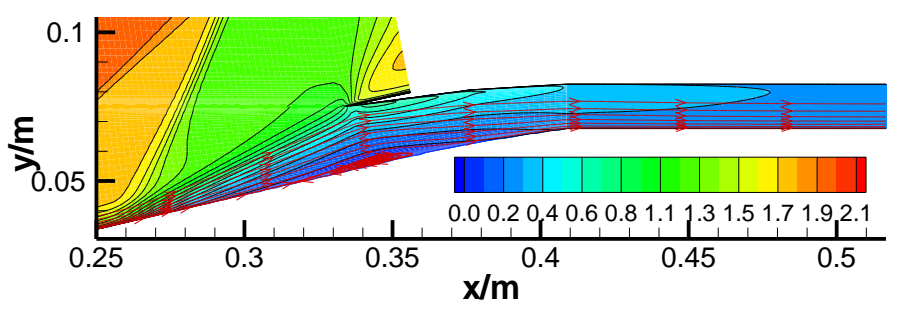

(a) Flight Mach number is accelerated to 2.02

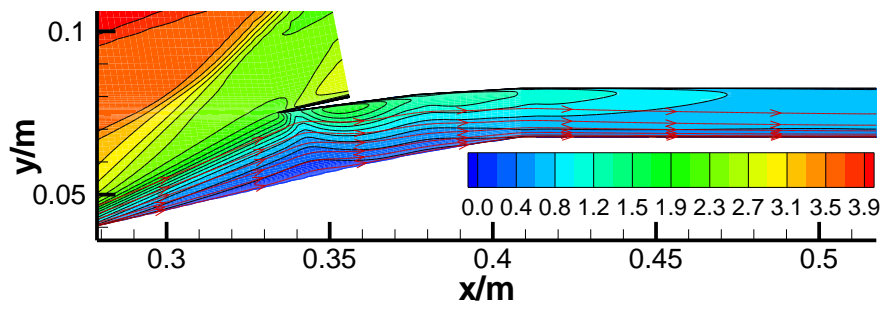

(b) Flight Mach number is accelerated to 4.05

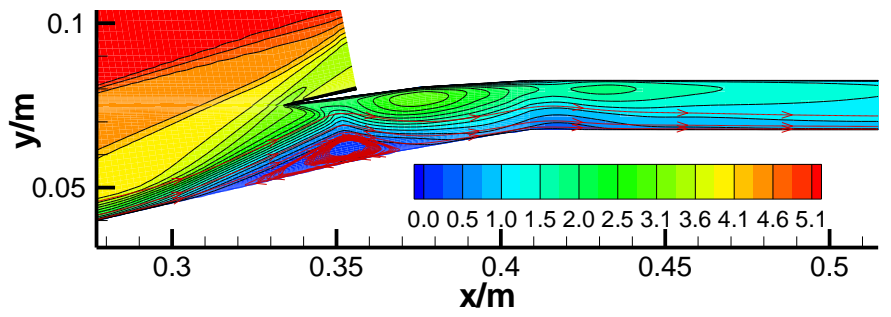

(c) Flight Mach number is accelerated to 5.25

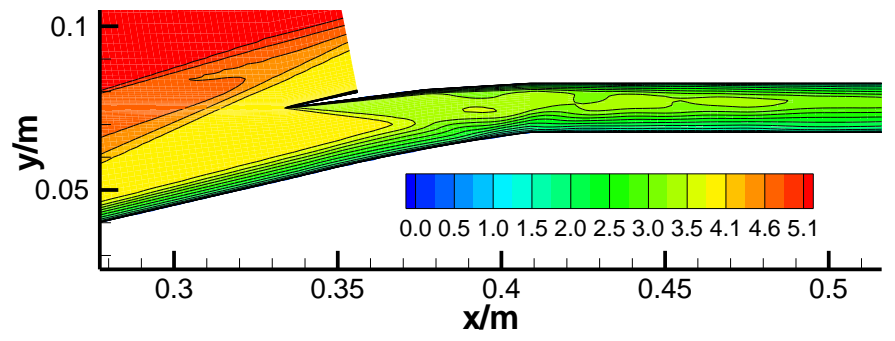

(d) Flight Mach number is accelerated to 5.5

Fig. 20 Sequence of Mach number in the restarting process for constant dynamic pressure trajectory,

$$
c_{0}=147.5 \mathrm{~s}^{-1}
$$

Fig. 19 and Fig. 20 illustrate that, in compare with the constant dynamic pressure trajectory, the inlet is easy to restart under the constant altitude trajectory. The impact of trajectory on the inlet restart is presented in Fig. 21, where the flight Mach number when the inlet restarts is plotted against the acceleration. It demonstrates that although the unstarted flow fields are the same, the inlet is easy to restart for the constant altitude trajectory compared with the constant dynamic pressure trajectory. 
This may be attributed to the difference of the Reynolds numbers between the two trajectories during the accelerative restarting processes. For the constant dynamic pressure trajectory, the Reynolds number keeps decreasing with the increase of the flight Mach number. By contrast, the Reynolds number increases during the accelerative process for the constant altitude trajectory. For example, When the Mach number of vehicle is accelerated to 4.5 under constant dynamic pressure trajectory, The Reynolds number is only $20 \%$ of the one that is accelerated under constant altitude trajectory.

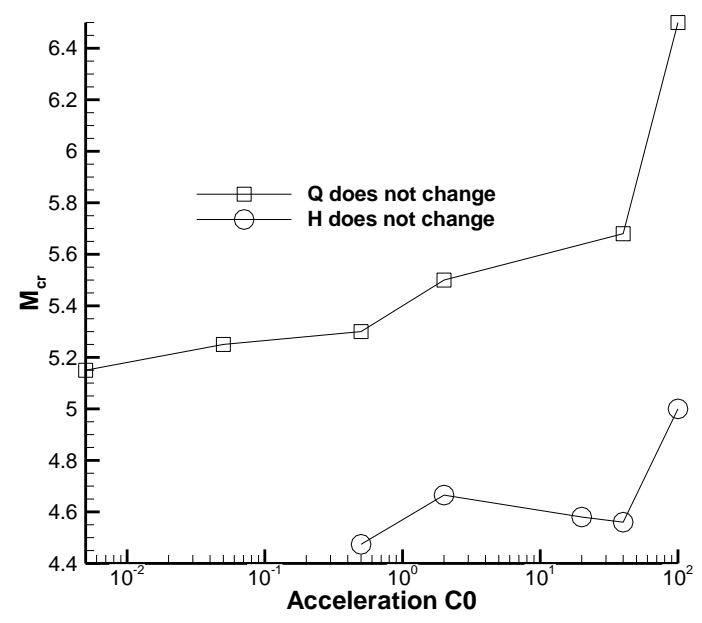

Fig. 21 Relation of restart Mach number with acceleration $c_{0}$

\section{Discussion of Hysteresis}

The hysteresis graph with dimensionless mass flow rate is presented in Fig. 22, which shows that there is hysteresis in the restarting process. For the acceleration of 1.475, restart occurs at the Mach number of 5.16 if it is accelerated from an unstarted flow field. However, if it is decelerated from a started flow field, unstart will not occur until Mach number is decreased to 2.76 . Fig. 22 also indicates that the hysteresis loop increases with the increase of acceleration. 


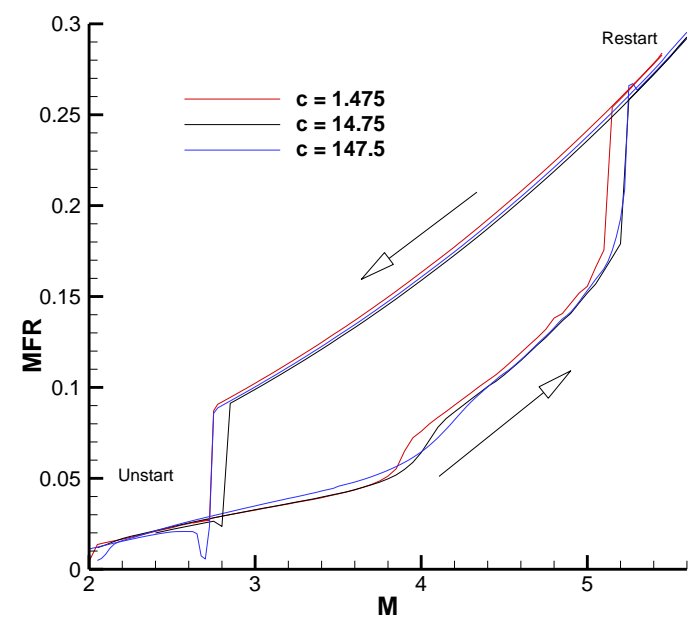

\section{Fig. 22 Hysteresis diagram with dimensionless mass flow rate}

Fig.23 gives the hysteresis graph under different trajectories. Compared with the effect of acceleration, it shows that the trajectory has a major impact on the hysteresis. The hysteresis loop under constant dynamic pressure trajectory is larger than that of constant altitude trajectory.

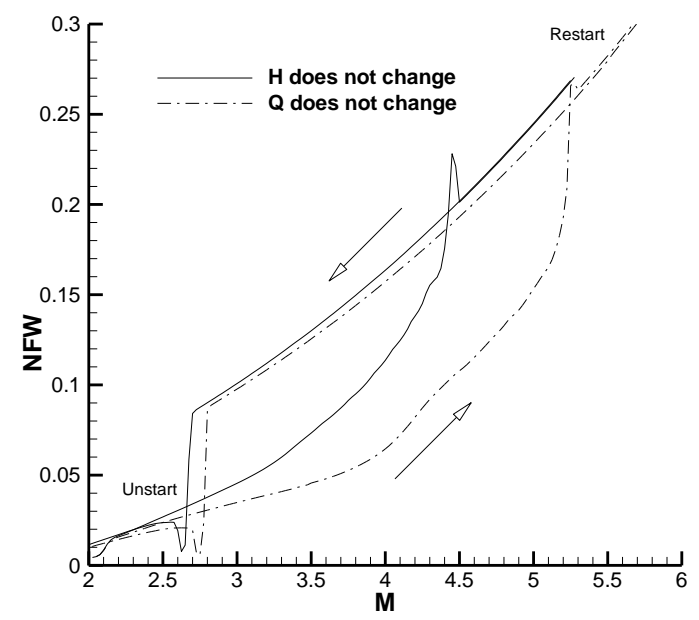

\section{Fig. 23 Hysteresis graph under different trajectories}

\section{Conclusions}

Unsteady RANS simulations were carried out to investigate the accelerative restarting processes of a twodimensional planar inlet. The characteristics of the accelerative restart process were examined. The results show that the inlet restarting state can be monitored by the time histories of wall pressure within the inlet. The effects of acceleration and trajectories on the inlet restart were investigated. The results indicate that acceleration-induced unsteadiness can cause the inlet choked more seriously. Therefore, the disappearance of the separation bubble is 
delayed such that the corresponding Mach number at which the inlet restart increases accordingly compared with the accelerative restart process at lower acceleration. The unsteady computational results also reveal that although the acceleration affects the restarting process significantly, after the inlet restarts, the restart flow in the inlet is not affected by the magnitude of acceleration. The research also displays that the trajectory has great impact on the restart of hypersonic inlet. The constant altitude trajectory has a smaller restart Mach number and smaller hysteresis compared with the constant dynamic pressure trajectory.

\section{Acknowledgments}

The work was supported by the National Natural Science Foundation of China through Grant 11102087, 11572155 and the Fundamental Research Funds for the Central Universities through Grant NS2015018.

\section{References}

[1] VanWie, D. M., Kwok F T, Walsh R F, “Starting Characteristics of Supersonic Inlets,” AIAA paper 96-2914, 1996. doi: 10.2514/6.1996-2914

[2] Kantrowitz, A., Donaldson, C., "Preliminary Investigation of Supersonic Diffusers,” NACA WRL-713, 1945.

[3] Im, S-K, Do, H., Mungal, M.G., Cappelli , M. A. , "Experimental Study and Plasma Control of an Unstarting Supersonic Flow," AIAA paper 2012-2809, 2012.

doi: $10.2514 / 6.2012-2809$

[4] Valdivia,A., Yuceil, K. B., Wagner „J.L., Clemens, N.T., Dolling ,D.S., “Control of Supersonic Inlet-Isolator Unstart Using Active and Passive Vortex Generators," AIAA Journal,2014, Vol. 52, No.6, pp. 1207-1218. doi: $10.2514 / 1 . J 052214$

[5] Hutchins, K. E., Akella, M. R., Clemens, N.T., Donbar, J.M., "Detection and Transient Dynamics Modeling of Experimental Hypersonic Inlet Unstart,” AIAA paper 2012-2808, 2012. doi: $10.2514 / 6.2012-2808$

[6] Varadarajan, P. A., Roe, P. L., “Geometrical shock dynamics and engine Unstart,” AIAA paper 2011-3909, 2011. doi: 10.2514/6.2011-3909

[7] Segal, C, “The Scramjet Engine: Processes and Characteristics," Cambridge University Press, New York, 2009. doi: 10.1017/CBO9780511627019 
[8] Ogawa, H., Grainger, A. L., Boyce, R. R., "Inlet Starting of High-Contraction Axisymmetric Scramjets,” Journal of propulsion and power, 2010, Vol. 26, No.6, pp. 1247-1258.

doi: $10.2514 / 1.48284$

[9] Grainger, A. L., Boyce, R. R., Tirtey, S. C., Ogawa, H., “The Unsteady Flow Physics of Hypersonic Inlet Starting Processes,” AIAA paper 2012-5937, 2012.

doi: $10.2514 / 6.2012-5937$

[10] Grainger, A. L., Tirtey, S. C., Boyce, R. R., Malpress, R., Buttsworth, D., "Investigation into the Flow Physics of Hypersonic Variable Geometry Inlet Starting,” AIAA paper 2014-3230, 2014.

doi: $10.2514 / 6.2014-3230$

[11] Grainger, A. L., Paniagua, G., "Starting Processes of High Contraction Ratio Scramjet Inlets,” AFRL-AFOSR-UK-TR-20110061, 2012.

[12] Throckmorton, R., Schetz, J., Jacobsen ,L., "Experimental and Computational Investigation of a Dynamic Starting Method for Supersonic/Hypersonic Inlets,” AIAA paper 2010-589, 2010.

doi: $10.2514 / 6.2010-589$

[13] Tam C-J, Hagenmaie, M., "Unsteady Analysis of Scramjet Inlet Flowfields Using Numerical Simulations,” AIAA paper 99$0613,1999$.

doi: $10.2514 / 6.1999-613$

[14] Hagenmaie, M., Tam C-J, Chakravarth, S., "Study of Moving Start Door Flow Physics for Scramjets," AIAA paper 99-4957, 1999.

doi: $10.2514 / 6.1999-4957$

[15] VanWie, D. M., "Scramjet inlets," Scramjet Propulsion, edited by Curran E T and Murthy S N B, Progress in Astronautics and Aeronautics, AIAA, Washington, DC, 2000, pp. 463-466.

doi: $10.2514 / 4.866609$

[16] Williams, R. L., “Application of Pulse Facilities to Inlet Testing,” Journal of Aircraft, 1964, Vol.1, No.10, pp.236-241. doi: $10.2514 / 3.43589$

[17] McGregor, R., Molder, S., and Paisley, T., "Hypersonic inlet Flow starting in Ryerson /University of Toronto Gun Tunnel," Investigation in the Fluid Dynamics of Scramjet Inlets, Ryerson Polytechnic Inst. and Univ. of Toronto, Canada, July 1992.

[18] Tahir, R. B., Molder, S., Timofeev, E. V., “Unsteady Starting of High Mach Number Air Inlets - a CFD Study,” AIAA paper 2003-5191, 2003.

doi: 10.2514/6.2003-5191 
[19] Timofeev, E. V., Tahir, R. B., Molder, S., “On Recent Developments Related to Flow Starting in Hypersonic Air Intakes,” AIAA paper 2008-2512, 2008.

doi: $10.2514 / 6.2008-2512$

[20] Voland, R.T. , Auslender, A. H., Smart, M. K., Roudakov,A. S., Semenov ,V.L., Kopchenov, V., "CIAM/NASA Mach 6.5 scramjet flight and ground test," AIAA paper 99-4848, 1999. doi: 10.2514/6.1999-4848

[21] Menter, F. R., “Two-equation eddy-viscosity turbulence models for engineering applications,” AIAA Journal, 1994, Vol. 32, No.8, pp. 269-289. doi: $10.2514 / 3.12149$

[22] Wilcox, D. C., "Dilatation-dissipation corrections for advanced turbulence models," AIAA Journal, Vol. 30, No. 11, 1992, pp.2639-2636.

[23] Einfeldt, B., “On Godunov-type Methods for Gasdynamics,” SIAM Journal on Numerical Analysis, Vol. 25, No. 2, 1988, pp. $294-318$

doi: 10.1137/0725021

[24] Blazek, J., “Computational Fluid Dynamics: Principle and Applications,” $1^{\text {st }}$ ed., Elsevier Science Ltd., New York, 2001, pp.44.

[25] Yang, G. W., Obayashi, S., Nakamichi, J., "Aileron Buzz Simulation Using an Implicit Multiblock Aeroelastic Solver ," Journal of Aircraft ,Vol. 40, No. 3, 2003, pp.590-589. doi: $10.2514 / 2.3134$

[26] Wei-Yi Su, Kun-Yuan Zhang, "Back-Pressure Effects on the Hypersonic Inlet-Isolator Pseudoshock Motions," Journal of Propulsion and Power, Vol.29, No.6, 2013, pp. 1391-1399. doi: 10.2514/1.B34803

[27] Krist, S. L., Biedron, R. T., Rumsey, C. L., “CFL3D User's Manual (Version 5.0),” NASA TM-1998-208444, 1998.

[28] Carlson J. R., "Prediction of very high Reynolds number compressible skin friction,” AIAA paper 1998-2880, 1998. doi: 10.2514/6.1998-2880

[29] Settles, G. S., d Dodson, L. J., "Hypersonic Shock/Boundary-Layer Interaction Database: New and Corrected Data,” NASA CR 177638, 1994.

[30] Li, F., Choudhari, M., Chang, C.-L., Kimmel, R., Adamczak, D., Smith M., "Transition Analysis for the Ascent Phase of HIFiRE-1 Flight Experiment,” Journal of Spacecraft and Rockets, Vol. 52, No. 5, 2015, pp. 1283-1293. doi: 10.2514/1.A33258 